\title{
THE EYE OF THE BEHOLDER: HOTEL COMPANY CEO PERCEPTIONS OF THREATS AND OPPORTUNITIES
}

\section{Tony Simons}

\section{Karthik Namasivayam}

\section{Cornell University}

The chief executive officers (CEOs) of 96 multisite, U.S.-based hotel owner/operator companies were interviewed and asked to describe the dominant upcoming threats and opportunities they perceived for their segment. Responses converged in describing two major threats (overbuilding and economic downturn) but were far more divergent in descriptions of opportunities. This pattern may emerge from the nature of threats and opportunities, from quirks of information dissemination and processing in the hotel industry, or from systematic biases in the perception of CEOs. Our data provide strong evidence of the impact of segment on threat and opportunity perceptions, as is appropriate to a rational model. Tests of potentially influential factors at the CEO and team levels provided no evidence of bias.

KEYWORDS: environmental scanning; executive decisions; strategy process; SWOT analysis; strategic issue diagnosis. 
Information about the business environment does not come prepackaged into clean strategic issues - it is, by its nature, complex, vague, and ambiguous (Daft \& Weick, 1984; Dutton, Fahey, \& Narayan, 1983; Walsh, 1995). Strategic issues must be interpreted. They are not given in the environment (Jackson \& Dutton, 1988). If organizational success is influenced by strategic choice, and if strategic choice is in turn driven by issue interpretation (e.g., Daft \& Weick, 1984), then executives' interpretation processes are pivotal to organizational success. It is therefore crucial to understand how managers gather information and how they analyze and categorize the data in their environments.

Recently, there has been considerable debate in the strategic management literature about the magnitude of the role of deliberate and rational strategic planning (e.g., Hitt \& Tyler, 1991; Mintzberg, 1994; Rajagopalan, Rasheed, \& Datta, 1993; Schwenk, 1995). This debate might be seen as casting doubt on the importance of strategic issue-diagnosis processes. However, we assert that executives' scanning, issue identification, and interpretation processes are of considerable importance regardless of whether strategic action is seen as primarily deliberate or emergent, rational or not, long-term or short-term. Executives' understandings of environmental forces determine their strategic actions (Schneider \& DeMeyer, 1991). Executives' interpretations of threats and opportunities in the financial realm, in markets, technology, and elsewhere, influence how they manage their companies. If one allows that executives are capable of strategic action or response, then environmental scanning and interpretation processes must be recognized as playing a pivotal role in organizational functioning.

Executive interpretation of environmental issues defines subsequent organizational adaptations to environment (Daft \& Weick, 1984; Lant, Milliken, \& Batra, 1992) and drives strategic choices (Boulton, Lindsay, Franklin, \& Rue, 1982; Dean \& Sharfman, 1996; Dutton \& Jackson, 1987). Executives' interpretations of the environment can also influence the processes by which strategic choices are made (Jackson \& Dutton, 1988; Staw, Sandelands, \& Dutton, 1981). In addition, interpretations tend to influence future perceptions: It is well-documented that an observer's beliefs and expectations tend to bias perceptions toward confirmation (e.g., Fiske \& Taylor, 1991). The impact of labels on perception and decision processes is especially important in issue diagnosis, because diagnosis in turn influences executives' future interpretations of the environment (e.g., Beyer, Chattopadhyay, Glick, \& Pugliese, 1997; Jackson \& Dutton, 1988). Executive interpretations influence critical decisions, and, perhaps more critically, influence future perceptions and interpretations: Executive perceptions tend to snowball as they accrue confirmatory evidence.

Some empirical research has explored these critical processes in hospitality companies. Costa (1995) reviewed the environmental scanning literature and dis- cussed its application to hospitality. Costa and Teare (1994) discussed Portuguese hotel companies' business environments and reviewed literature on environ- mental scanning. Olsen, Murthy, and Teare (1994) explored the scanning processes and threat or opportunity perceptions of 54 international hospitality chief executive officers (CEOs). The present work updates that of Olsen et al. to the current business environment and examines a larger sample of U.S.-based companies. 
Furthermore, we extend the stream of research by examining factors at the company level, the CEO level, and the top management team level that might influence CEO perceptions.

\section{Rational Influences on Strategic Issue Interpretation}

Hypothesis 1: Strategic issue perception will be affected by the following rational factors: (a) primary market segment, (b) ownership structure, and (c) company size.

Strategic issues in the environment are likely to have different practical implications for different companies (Rajagopalan et al. , 1993). For example, companies that serve different market segments will be affected, to some extent, by different factors. A market trend that affects one group of customers might not affect another, and competition in one segment might have only a slight effect on other segments. The ownership structure of companies is likely to affect strategic issue interpretation, as subsidiary companies, privately held companies, and publicly traded companies face different capital environments. Opportunities that require capital or that make capital available may look different to CEOs who operate in different capital environments. Likewise, a stock market downturn might easily represent a threat for a publicly traded company and an opportunity for a privately held company: Although a downturn might reduce leisure travel across the board, it would also put privately held companies at an advantage from a capital- generation standpoint. Finally, company size could serve as a buffer to many threats, as a large company could presumably weather more environmental turbulence than a small one.

These arguments describe internal factors that can be expected to influence the actual strategic importance of a given environmental occurrence. The impact of these variables on strategic issue diagnosis may be considered rational, as they derive from an organization's perceived capacity to respond effectively to an environmental event. They are represented in Hypothesis 1.

\section{Individual-Level Influences on Strategic Issue Interpretation}

Hypothesis 2: Strategic issue perception will be affected by the following CEO characteristics: (a) primary functional background, (b) tenure, (c) education, and (d) cognitive style.

There are several nonrational factors that might influence issue interpretation. CEO perceptions of strategic issues in their environments are influenced by individual cognitive processes and biases (Beyer et al. , 1997; Schwenk, 1995; Stubbart, 1989). When an individual decision maker faces relevant information that is ambiguous and complex, he or she will tend to simplify that information using heuristics or rules of thumb (Mintzberg, Raisinghani, \& Theoret, 1976; Stubbart, 1989). Walsh (1995) suggests that ambiguous streams of strategic environmental information are made understandable by the application of knowledge structures or cognitive maps that are formed in the minds of decision makers as a result of prior experiences. Jackson and Dutton (1988) describe this process as schema- driven information processing.

Two dominant schemas are the ideas of threats and opportunities, which have long been applied to strategic environmental interpretation (Dutton \& Jackson, 1987). Once an issue has been 
labeled an opportunity or a threat by the senior executive, it tends to be widely recognized as such by the other members of the organization (Dutton \& Jackson, 1987; Dutton et al. , 1983; Jackson \& Dutton, 1988). Furthermore, the identification of a given issue as a threat tends to shape further consideration of and response to that issue, both by individual decision makers and by groups (Jackson \& Dutton, 1988; Staw et al. , 1981).

Hambrick and Mason (1984) proposed that executives' functional back- grounds, educations, and other personal attributes influence the environment elements to which they are sensitive and the strategic responses they propose. Evidence for this proposed influence has been found by Walsh (1988) and Beyer et al. (1997). One reason for this influence is that executives are likely to interpret ambiguous events as being similar to events they have experienced previously, because some attributes of the event might be familiar. Prahalad and Bettis (1986) describe this pattern, noting that the reasoning by analogy that results is sometimes inappropriate. They argue that executives' previous response modes have been reinforced by prior successes and that this reinforcement inhibits the perception of events in novel ways. Starbuck and Milliken (1988) suggest that executives will tend to favor strategies that will keep their tasks central to the operation of the company. Walsh (1988) and Beyer et al. (1997) also found evidence for a relation- ship between managers' functional backgrounds and their interpretations of ambiguous stimuli.

Similar reasoning supports the notion that executive perceptions will be influenced by the length of their tenure in the position and by their level and type of education. Executives who have experienced a particular type of industry crisis during their tenure are likely to be more sensitive to signs of a repeat of that crisis. Advanced education might also affect perception and interpretation, as advanced management courses typically spend time focusing on patterns of strategic issues. Environmental scanning procedures and interpretation processes learned in school are likely to carry over into executives' professional careers.

Finally, executive attributes such as intelligence or cognitive style might influence their strategic issue diagnoses. Stubbart (1989) and Ungson, Braunstein, and Hall (1981) emphasize the fact that issue diagnosis is fundamentally a cognitive process. Thus, CEOs' cognitive habits and proclivities are likely to influence it. The above arguments focus on the impact of individual perceiver characteristics on strategic issue diagnosis and are represented in Hypothesis 2.

\section{Organizational and Institutional Influences on Issue Interpretation}

Hypothesis 3: Strategic issue perception will be affected by the following company characteristics: (a) company age and (b) top management team climate.

Issue interpretation does not happen in a vacuum, and CEO interpretations are likely to be influenced by aspects of the organization and of the institutional environment they inhabit. Daft and Weick (1984) suggest that the age of the organization influences issue interpretation, as company history or prior experience influences the perception of ambiguous stimuli. This 
process is similar to executives' analogical reasoning as described by Prahalad and Bettis (1986) but focuses on organizational memories rather than individual ones.

Dutton et al. (1983) describe a negotiation process whereby organization members pool their beliefs and determine the organization's shared belief structures through political maneuvering and confrontation. The impact of executive group political climate on issue diagnosis has similarly been indicated by Schwenk (1995) and Rajagopalan et al. (1993). Within a negotiation over shared issue interpretations, the credibility of different executive group members (Fiske $\&$ Taylor, 1991) is also likely to determine which group members exert the most influence over the outcome. The political climate of the top management group - its level of true participative discussion, intragroup trust, and collaboration - is likely to influence the potential impact of group members other than the CEO. These lines of reasoning are represented in Hypothesis 3.

Hypothesis 4: Strategic issue perception will be affected by the frequency of issue coverage in the industry press.

Finally, issue interpretation is likely to be influenced by the larger institutional climate in which hotel companies operate. Aldrich and Pfeffer (1976) note that executive perceptions in a given industry are likely to be influenced by their shared exposure to the coverage of strategic issues in trade journals. Starbuck (1975) notes that executive perceptions will be affected by shared membership in industry associations and attendance at conferences and trade shows. Sutcliffe and Huber (1998) find that industry influences strategic perceptions, but they do not disentangle rational elements of this influence from nonrational elements. Executives remember the explanations that the industry press has presented to them for massive failures or successes in recent history, and these memories are likely to color their perceptions of their current business environment. Institutional forces are represented in Hypothesis 4.

\section{METHOD}

The CEOs of 96 multisite, U.S.-based hotel companies agreed to participate in this research in return for a benchmarked feedback report on their company's executive group process. These companies were drawn from the American Hotel \& Motel Association membership directory, were U.S.-based, and were owner- operators of at least three properties.1 Operating revenues for participating companies ranged from $\$ 1.9$ million to more than $\$ 600$ million, with median revenues of $\$ 37$ million. The median participating company size was 8 properties. The average company size was 42.8 properties, but excluding the largest 2 companies from this calculation dropped the average size to 23.5 properties. The companies represented a range of segments: 54 of the participating CEOs identified their primary segment as mid-priced, 20 defined theirs as economy, and 16 defined theirs as luxury.

The principal investigator conducted 1-hour telephone interviews with the participating CEOs.3 Early in the interviews, the CEOs were asked, "First, I would like to ask you about your company's business environment. What do you see as the single most important source of business opportunities for your segment of the hotel industry over the next few years," followed by the analogous question, phrased identically, for business threats. Executives were thus encouraged to offer a single, brief response-essentially the most vivid threat or opportunity that 
came to mind. Responses to these questions were written down and were later categorized for statistical purposes.

To supplement and help explain CEO perceptions of threats and opportunities, we gathered information about the company, about the CEO personally, and about the top management group dynamics. This additional data were gathered in the remainder of the interview, through paper surveys completed by the rest of the top management group at each company (as identified by the $\mathrm{CEO}$ ), and through a financial and operational performance questionnaire sent separately to the company's financial officer. Of the 96 companies, 78 provided at least one additional top management team member survey, and 60 companies completed the financial and operational performance questionnaire.

Company-level factors were expected to influence CEO perceptions of threats and opportunities by affecting the resources available to each company, the his- tory through which it had passed, the customer base, and, as a result, what factors actually might present threats or opportunities to that company. Most of these company-level factors could be considered as affecting the true picture of threats and opportunities, rather than affecting primarily the perception of same. These variables were measured from a variety of sources: Market segment, as noted above, was specified by the CEO during the interview. Company size was measured through the financial and operational performance questionnaire, as the total number of employees or full-time equivalents managed by the company. Company age was assessed as years since founding. Both company size and age were transformed, using a logarithmic transformation to correct skewed distributions.5 On the operational questionnaire, we also asked whether the company was privately held, reasoning that ownership structure would influence the CEOs' sensitivity to fluctuations in financial markets.

CEO personal data was assessed as a factor that might influence which environmental factors attract the top executive's attention and how information is processed. This data was assessed primarily through the interview. CEOs were asked when they assumed their current position to determine tenure, which was, in turn corrected for skew using a logarithmic transformation. CEOs were also asked to specify their primary functional background and their highest academic degree earned. This latter piece of information was treated both as a categorical and as a continuous variable (by translation into "years of education"). Results between the two operationalizations of CEO education were the same, and so only "years of education" results are reported here. Finally, CEO cognitive style was assessed using Neuberg and Newsome's (1993) "personal need for structure" scale, which assesses a dispositional difference in motivation to cognitively structure the world in simple, unambiguous ways. The coefficient alpha for this 11item scale was .80 .

Top management group processes were considered as a possible influence on CEO perceptions. Specifically, we imagined that CEOs whose top management groups practiced more collaboration might be more likely to identify threats and opportunities in functional areas other than their own. Collaboration was measured using the averaged perceptions of top management group members and was assessed with a scale based on Putnam and Wilson's (1982) 
Organizational Conflict and Communication Inventory (OCCI). Cronbach's alpha for this 5-item scale was .81 .

To assess industry press coverage of a particular threat or opportunity, we searched the International Hospitality and Tourism Database for articles published in calendar years 1995 and 1996, using keywords drawn from issue descriptions, as well as synonyms. We then checked each listing to make sure the topic was correctly categorized and tallied the total number of articles published during the years in question for each topic. Only those articles that had the topic in question as their primary focus were counted.

The extreme diversity of responses limited statistical analysis possibilities. However, a few responses occurred with sufficient frequency to allow for analysis: In response to the query on threats, 58 CEOs mentioned overbuilding, and 11 mentioned larger economic factors. In response to the query on opportunities, 16 CEOs mentioned commercial business, and 11 mentioned leisure travel. Thus, we created dummy variables for these four strategic issue identifications and used logistical regression and chi-square tests to assess the impact of continuous and categorical predictor variables, respectively, on the frequency of these strategic issue diagnoses. Our analysis is limited, then, to an exploration of whether the predictive factors described in Hypotheses 1 through 4 influence the likelihood of CEOs' identifying the two most popular threats or opportunities. Given the high number of categorical variables in this study design, we could not generate a correlation matrix of all variables.

By drawing on additional personal and company information provided by the CEO and other senior executives, we were able to assess the impact of market segment, company size, ownership structure, company age, CEO tenure, CEO functional background, CEO cognitive style, top management group collaboration, and industry press on the CEOs' identification of overbuilding and the economy as potential sources of threat and of commercial and leisure travel as sources of opportunity.

\section{RESULTS}

Tables 1 and 2 show the CEO responses, broken down by market segment. Table 3 shows a correlation matrix of the predictors and the four most frequent CEO responses.

Hypothesis 1a was supported by these data. Market segment influenced CEOs' identification of overbuilding as a primary threat (chi-square $=12.31, d f=3, p<.01$ ). Economy companies were most likely to identify overbuilding as a threat, followed by mid-price and luxury segments. Out of 20 economy companies, 16 identified overbuilding, as did 35 out of 54 mid-price companies and 4 out of 16 luxury companies. Market segment did not significantly affect CEOs' identification of the economy or wars as a primary threat (chi-square $=4.50, d f=3$, n.s.), of business travel as an opportunity (chi-square $=3.14, d f=3$, n.s.), or of leisure travel as an opportunity (chi-square $=1.57, d f=3$, n.s.).

Hypothesis $1 \mathrm{~b}$ received moderate support from these data. Company owner- ship structure had a marginal effect on CEOs' identification of overbuilding as a primary threat (chi-square $=3.21, d f$ $=1, p<.10$ ). Out of 45 privately held companies, 28 identified overbuilding as a threat, 
compared to only 4 out of 12 publicly traded companies. There was no significant effect on CEOs' identification of the economy or wars as a primary threat (chi-square $=0.27, d f=1$, n.s.). Ownership structure had a marginal effect on identification of business travel as a primary opportunity (chi-square $=3.63, d f=1, p<.10$ ). In our sample, no publicly traded companies identified business travel as a key opportunity, whereas several private companies did. Ownership structure had no significant effect on the identification of leisure travel as a primary source of opportunity (chi-square $=0.01, d f=1$, n.s.).

Hypothesis 1c received only weak support from these data. Company size had no significant effect on the identification of overbuilding or the economy as primary threats $(b=.12$, n.s.; and $b$ $=-.15$, n.s., respectively). However, company size had a marginally significant effect on the identification of business travel as a source of opportunity $(b=-.64, p<.10)$, with larger companies tending not to select business travelers as an opportunity. Company size had no significant effect on the identification of leisure travel as a source of opportunity $(b=.00$, n.s.).

Hypothesis 2a received only weak support from these data. CEO functional background had no significant effect on the identification of overbuilding or the economy as primary threats (chisquare $=5.30, d f=8$, n.s., and chi-square $=4.06, d f=8$, n.s., respectively). CEO functional background had a marginally significant effect on the identification of business travel as a source of opportunity (chi- square $=14.75, d f=8, p<.10$ ). CEOs were most likely to select this opportunity when their functional background was in human resources or in something nontraditional. CEO functional background had no significant effect on the identification of leisure travel as a source of opportunity (chi-square $=5.65, d f=8$, n.s.).

Hypothesis $2 \mathrm{~b}$ was only weakly supported by these data. Length of CEO tenure had a marginally significant effect on the identification of overbuilding as a primary threat $(b=.33, p<.10)$ and had no significant effect of the identification of the economy as a primary threat $(b=-.26$, n.s.). CEO tenure had no significant effect on the identification of business or leisure travel as a key source of opportunities ( $b=-.09$, n.s.; and $b=.55$, n.s., respectively).

Hypothesis $2 \mathrm{c}$ was not supported by these data. Years of CEO education had no significant effect on the identification of overbuilding or the economy as primary threats $(b=.15$, n.s.; and $b=$ .04 , n.s., respectively), or on the identification of business or leisure travel as a key source of opportunities ( $b=-.19$, n.s.; and $b=-.24$, n.s., respectively).

Hypothesis $2 \mathrm{~d}$ was not supported by these data. CEO need for simple structure had no significant effect on the identification of overbuilding or the economy as primary threats $(b=.02$, n.s.; and $b=.01$, n.s., respectively), or on the identification of business or leisure travel as a key source of opportunities ( $b=.03$, n.s.; and $b=.00$, n.s., respectively).

Hypothesis 3a received marginal support from these data. Company age had a marginally significant effect on the assessment of overbuilding as a primary threat $(b=-.70, p<.10)$ and on the assessment of the economy as a source of threat $(b=1.39, p<.10)$. CEOs of older companies were slightly more likely to note the economy and less likely to note overbuilding as pivotal threats. Company age had no significant effect on the identification of business or leisure travel as a source of opportunity ( $b=-.19$, n.s.; and $b=.19$, n.s., respectively) 
Hypothesis $3 \mathrm{~b}$ was not supported by these data. Top management group collaboration had no significant effect on the identification of overbuilding or the economy as primary threats $(b=.09$, n.s.; and $b=-.15$, n.s., respectively), or on the identification of business or leisure travel as a key source of opportunities ( $b=.23$, n.s.; and $b=-.15$, n.s., respectively).

Hypothesis 4 received support from these data, as the frequency of issue cover- age in the industry press substantially paralleled CEOs' rankings. The threat of overbuilding was the most frequently discussed business threat in the industry press, with 20 articles. This frequency matched the very frequent CEO mention of overbuilding as the key business threat. Two issues were tied at second most frequently mentioned in the industry press, with 15 articles each: They were (a) pressure on room tariffs due to business cycles or a slowdown of the economy and (b) human resource-related issues such as employee retention and turnover. The economy was the CEOs' second most frequently mentioned source of threat. However, despite frequent press attention, human resource issues were high- lighted by only a single CEO out of 96. Of the mentioned opportunities, local economic growth was the most frequently described by industry journals, with 35 articles. However, only $5 \%$ of CEOs mentioned this source of opportunity. Commercial business and leisure travel were considered to be very important opportunities by the CEOs. These issues were the second and third most frequently mentioned opportunities in the industry press, with 25 and 15 articles respectively.

\section{DISCUSSION}

The most striking result of this research is the clear dominance of overbuilding as the primary threat noted by more than $60 \%$ of the CEOs surveyed in this study. No such convergence was evident for the category of opportunities. It is possible that this contrast represents a fundamental difference between opportunities and threats: Perhaps threats are universal, whereas opportunities by their nature must be relatively unique for each company if they are to generate competitive advantages. It is also possible that the difference in convergence emerges from Jackson and Dutton's (1988) observation that CEOs are reluctant to disavow a threat once it is detected, whereas they show great readiness to disavow detected opportunities. Jackson and Dutton's argument implies that threat perceptions are more long-lived than are opportunity perceptions, and so convergence between CEOs might have a greater chance to develop. The question of whether the difference in convergence is fundamental to the nature of threats and opportunities, or whether it emerges instead from the different cognitive processes that are evoked by consideration of positive and negative outcome potentials, is an issue for future examination. Likewise, there remains the question of whether the observed convergence pattern would hold in a different business environment or in a different year.

The predictors described as rational factors in strategic issue diagnosis received the best support from these data. Selected market segment influenced the perception of overbuilding as a threat, and there was marginal evidence that ownership structure influenced perceptions of both threats and opportunities. Company age, which can be considered as a company-level perceptual filter, received marginal support as an influence factor. There was little support for the influence of individual CEO perceptual factors or other company-level influences on threat and opportunity recognition. The frequency of articles in the industry press was associated with CEOs' issue 
diagnoses, although some issues received substantial press but were seldom noted by CEOs as being of central importance. Labor shortages were discussed at length in the industry press but were seldom mentioned by the company CEOs, perhaps because they tend to consider staffing a local or operational issue rather than a strategic one. Local economic growth was high- lighted strongly by the press but was mentioned as an opportunity by only five CEOs. It is possible that economic growth represents a positive environmental factor that CEOs perceive as being out of their control, and therefore it might not fit well with the mental category of opportunity (Dutton \& Jackson, 1987; Jackson \& Dutton, 1988). Whether industry press represented a causal factor or a simple reflection of industry reality cannot be distinguished in these data.

The results of this study should not be interpreted to mean that cognitive biases and top management group process do not exert influence on the strategic issue- diagnosis process.

Logistical analysis has very low power for the detection of real effects that sway as little as $10 \%$ of the sample population, and so this may be viewed as a very conservative test of most of these hypotheses. Furthermore, null results can emerge from a variety of causes, and the design of the current study allowed for only single operationalizations of group process and cognitive style. A future study might focus primarily on these factors and thus allow for more and varied operationalizations. Future studies might also allow CEOs to list and prioritize several potential threats and opportunities, rather than just the primary threat and opportunity. Such an expansion would allow for more fine-grained analysis and could further clarify this important area of organizational research.

In sum, this study examined perceptions of threats and opportunities by 96 hotel company CEOs. The vast majority of them converged in describing over- building as the key business threat for the coming years, but there was no such convergence for opportunities. The source of convergence in describing threats is not yet clear, nor is the lack of convergence in describing opportunities explained. Rational issue-diagnosis factors such as segment and ownership structure influenced CEO perceptions, but there was sparse evidence of nonrational influences on the process. Industry press coverage was associated with the frequency of CEOs' mention of different strategic issues, but there were several exceptions to this pattern. Although these results are not counterintuitive, they represent an important step in the systematic, empirical examination and clarification of a critical process in hospitality management.

It is perhaps early yet to derive practical implications from this research. The results could be interpreted to mean that managers are on the right track in their strategic thinking. However, the nonrational influences on senior managers' issue diagnosis processes should be considered as caveats even though the current study found little hard evidence to support them. Managers' use of the industry press in diagnosing threats and opportunities should also be considered carefully: It is very curious that one of the most commonly noted issues - a labor scarcity - was noted by only one of the CEOs as a potential threat. Managers' strategic thinking is affected by both rational and nonrational factors. The better these factors can be identified and measured, the more capable we will be of making logical decisions. 
Table 1

Threats Described by Hotel Company Chief Executive Officers, by Market Segment

\begin{tabular}{|c|c|c|c|c|c|c|c|c|c|c|}
\hline \multirow[b]{2}{*}{ Threat } & \multicolumn{2}{|c|}{ Economy } & \multicolumn{2}{|c|}{ Mid-Price } & \multicolumn{2}{|c|}{ Luxury } & \multicolumn{2}{|c|}{ Combination } & \multicolumn{2}{|c|}{ Row Total } \\
\hline & Frequency & $\%$ & Frequency & $\%$ & Frequency & $\%$ & Frequency & $\%$ & Frequency & $\%$ \\
\hline Overbuilding & 16 & 84.2 & 35 & 64.8 & 4 & 25.0 & 3 & 50.0 & 58 & 61.1 \\
\hline Economy, wars & 1 & 5.3 & 6 & 11.1 & 4 & 25.0 & 0 & & 11 & 11.6 \\
\hline Location competition $^{\text {a }}$ & 0 & & 2 & 3.7 & 2 & 12.5 & 0 & & 4 & 4.2 \\
\hline Location publicity ${ }^{\mathrm{b}}$ & 0 & & 3 & 5.6 & 0 & & 0 & & 3 & 3.2 \\
\hline Customer demand for perceived value & 0 & & 1 & 1.9 & 2 & 12.5 & 0 & & 3 & 3.2 \\
\hline National chains/franchisers & 1 & 5.3 & 0 & & 1 & 6.3 & 1 & 16.7 & 3 & 3.2 \\
\hline Big companies inflate property prices & 0 & & 1 & 1.9 & 2 & 12.5 & 0 & & 3 & 3.2 \\
\hline $\begin{array}{l}\text { Trend toward downsizing corporate } \\
\text { meetings }\end{array}$ & 0 & & 1 & 1.9 & 0 & & 1 & 16.7 & 2 & 2.1 \\
\hline Poor service execution & 0 & & 1 & 1.9 & 0 & & 1 & 16.7 & 2 & 2.1 \\
\hline Overpricing rooms & 1 & 5.3 & 0 & & 0 & & 0 & & 1 & 1.1 \\
\hline International travelers ${ }^{d}$ & 0 & & 1 & 1.9 & 0 & & 0 & & 1 & 1.1 \\
\hline Cost of travel & 0 & & 1 & 1.9 & 0 & & 0 & & 1 & 1.1 \\
\hline Fewer available management contracts & 0 & & 1 & 1.9 & 0 & & 0 & & 1 & 1.1 \\
\hline Scarcity of workers & 0 & & 1 & 1.9 & 0 & & 0 & & 1 & 1.1 \\
\hline Managerial complacency & 0 & & 0 & & 1 & 6.3 & 0 & & 1 & 1.1 \\
\hline Column total & 19 & 20.8 & 54 & 56.3 & 16 & 16.7 & 6 & 6.3 & 95 & 100.0 \\
\hline
\end{tabular}

a. Refers to competition for the served guest-base from other locations.

b. Refers to negative publicity for the location, as would be generated by crime statistics or vivid negative events in the news.

c. Refers to a reduction in the number of very large, national corporate meetings and their replacement by smaller regional meetings.

d. Refers to a tendency of target customers to travel abroad rather than stay in the United States. 
Table 2

Opportunities Described by Hotel Company Chief Executive Officers, by Market Segment

\begin{tabular}{|c|c|c|c|c|c|c|c|c|c|c|}
\hline \multirow[b]{2}{*}{ Opportunity } & \multicolumn{2}{|c|}{ Economy } & \multicolumn{2}{|c|}{ Mid-Price } & \multicolumn{2}{|l|}{ Luxury } & \multicolumn{2}{|c|}{ Combination } & \multicolumn{2}{|c|}{ Row Total } \\
\hline & Frequency & $\%$ & Frequency & $\%$ & Frequency & $\%$ & Frequency & $\%$ & Frequency & $\%$ \\
\hline Commercial business & 4 & 20.0 & 11 & 20.4 & 1 & 6.3 & 0 & & 16 & 16.7 \\
\hline Leisure travel & 3 & 15.0 & 7 & 13.0 & 1 & 6.3 & 0 & & 11 & 11.5 \\
\hline Underpriced acquisitions & 1 & 5.0 & 3 & 5.6 & 3 & 18.8 & 1 & 16.7 & 8 & 8.3 \\
\hline Groups and conventions & 1 & 5.0 & 4 & 7.4 & 2 & 12.5 & 0 & & 7 & 7.3 \\
\hline Repeat business, relationships & 2 & 10.0 & 2 & 3.7 & 1 & 6.3 & 2 & 33.3 & 7 & 7.3 \\
\hline \multicolumn{11}{|l|}{ Customer sensitivity to value } \\
\hline and service & 2 & 10.0 & 2 & 3.7 & 2 & 12.5 & 0 & & 6 & 6.3 \\
\hline Combining business and leisure trips & 1 & 5.0 & 4 & 7.4 & 0 & & 0 & & 5 & 5.2 \\
\hline Local economic growth & 1 & 5.0 & 5 & 9.3 & 0 & & 0 & & 6 & 6.3 \\
\hline Increase rates/ADR & 0 & & 2 & 3.7 & 2 & 12.5 & 0 & & 4 & 4.2 \\
\hline Consolidationacquisition & 2 & 10.0 & 1 & 1.9 & 0 & & 0 & & 3 & 3.1 \\
\hline Government business & 0 & & 3 & 5.6 & 0 & & 0 & & 3 & 3.1 \\
\hline \multicolumn{11}{|l|}{ Available resources and corporate } \\
\hline investors & 0 & & 2 & 3.7 & 0 & & 1 & 16.7 & 3 & 3.1 \\
\hline Underdeveloped locations & 1 & 5.0 & 1 & 1.9 & 0 & & 0 & & 2 & 2.1 \\
\hline Extended stay and time-share & 0 & & 1 & 1.9 & 0 & & 1 & 16.7 & 2 & 2.1 \\
\hline \multicolumn{11}{|l|}{ Increase occupancy } \\
\hline (especially off-peak) & 0 & & 1 & 1.9 & 1 & 6.3 & 0 & & 2 & 2.1 \\
\hline Provide value & 0 & & 1 & 1.9 & 0 & & 0 & & 1 & 1.0 \\
\hline Seniors & 0 & & 1 & 1.9 & 0 & & 0 & & 1 & 1.0 \\
\hline Lack of supply & 0 & & 0 & & 1 & 6.3 & 0 & & 1 & 1.0 \\
\hline Brand development & 0 & & 1 & 1.9 & 0 & & 0 & & 1 & 1.0 \\
\hline Obsolete supply in luxury segment & 0 & & 1 & 1.9 & 0 & & 0 & & 1 & 1.0 \\
\hline More transient business & 1 & 5.0 & 0 & & 0 & & 0 & & 1 & 1.0 \\
\hline Exit the economy segment & 1 & 5.0 & 0 & & 0 & & 0 & & 1 & 1.0 \\
\hline \multicolumn{11}{|l|}{ Overbuilding leads to third-party } \\
\hline management opportunities & 0 & & 1 & 1.9 & 0 & & 0 & & 1 & 1.0 \\
\hline Mid-priced products & 0 & & 0 & & 0 & & 1 & 16.7 & 1 & 1.0 \\
\hline Column total & 20 & 20.8 & 54 & 56.3 & 16 & 16.7 & 6 & 6.3 & 96 & 100.0 \\
\hline
\end{tabular}

Note: $A D R=$ average daily rate charged for rooms. 
Table 3

Means, Standard Deviations, and Correlations

\begin{tabular}{|c|c|c|c|c|c|c|c|c|c|c|c|c|c|}
\hline Variable $^{a}$ & Mean & $S D$ & 1 & 2 & 3 & 4 & 5 & 6 & 7 & 8 & 9 & 10 & 11 \\
\hline 1. Threat: Overbuilding & 0.58 & 0.50 & & & & & & & & & & & \\
\hline 2. Threat: Economy & 0.11 & 0.31 & $-.41^{\star \star}$ & & & & & & & & & & \\
\hline 3. Opportunity: Commercial business & 0.16 & 0.37 & .15 & -.07 & & & & & & & & & \\
\hline 4. Opportunity: Leisure travelers & 0.11 & 0.31 & .105 & -.02 & -.15 & & & & & & & & \\
\hline 5. Company age (years) & 22.39 & 14.97 & $-.22^{\dagger}$ & $.25^{\dagger}$ & -.06 & .05 & & & & & & & \\
\hline 6. Company size (number employed) & 1,703 & 2,858 & .08 & -.06 & $-.26^{\dagger}$ & .00 & -.01 & & & & & & \\
\hline 7. Privately owned & 1.79 & 0.41 & $24^{\dagger}$ & -.07 & $.25^{\dagger}$ & -.01 & -.01 & -.17 & & & & & \\
\hline 8. Years of CEO tenure & 12.17 & 9.14 & $18^{\dagger}$ & -.10 & -.04 & .15 & .21 & -.16 & $.23^{\dagger}$ & & & & \\
\hline 9. CEO education & 16.47 & 1.44 & .10 & .02 & -.11 & -12 & .07 & -.01 & .14 & .04 & & & \\
\hline 10. CEO's need for simple structure & 48.28 & 11.82 & .13 & .03 & .13 & -.01 & -.05 & -.17 & .12 & .09 & -.15 & & \\
\hline 11. Top management team collaboration & 20.90 & 1.94 & .09 & -10 & .15 & -.10 & $-31^{*}$ & -.07 & .11 & -.02 & .03 & -.09 & \\
\hline
\end{tabular}

Note: $C E O=$ chief executive officer.

a. $N=97$ for CEO variables, 79 for top management team variables, 57 for operational variables. Descriptives reported on untransformed variables. ${ }^{\dagger} p<0.10 .{ }^{*} p<0.05 .{ }^{* *} p<0.01$. 


\section{REFERENCES}

Aldrich, H., \& Pfeffer, J. (1976). Environments of organizations. Annual Review of Sociology, 2, 79-105.

Beyer, J. M., Chattopadhyay, P., George, E., Glick, W. H., \& Pugliese, D. (1997, June). The selective perception of managers revisited. Academy of Management Journal, 40, 716737.

Boulton, W. R., Lindsay, W. M., Franklin, S. G., \& Rue, L. W. (1982). Strategic planning: Determining the impact of environmental characteristics and uncertainty. Academy of Management Journal, 25, 500-509.

Costa, J. (1995). An empirically based review of the concept of environmental scanning. International Journal of Contemporary Hospitality Management, 7, 4-9.

Costa, J., \& Teare, R. (1994). Environmental scanning and the Portuguese hotel sector. International Journal of Contemporary Hospitality Management, 6, iv-vii.

Daft, R. L., \& Weick, K. E. (1984). Toward a model of organizations as interpretation systems. Academy of Management Review, 9, 284-295.

Dean, J. W., \& Sharfman, M. P. (1996). Does decision process matter? A study of strategic decision-making effectiveness. Academy of Management Journal, 39, 299-320.

Dutton, J. E., Fahey, L., \& Narayan, V. K. (1983). Toward understanding strategic issue diagnosis. Strategic Management Journal, 4, 307-323.

Dutton, J. E., \& Jackson, S. E. (1987). Categorizing strategic issues: Links to organizational action. Academy of Management Review, 12, 76-90.

Fiske, S. T., \& Taylor, S. E. (1991). Social cognition (2nd ed.). New York: McGraw-Hill.

Hambrick, D. C., \& Mason, P. A. (1984). Upper echelons: The organization as a reflection of its top managers. Academy of Management Review, 9(2), 193-206.

Hitt, M. A., \& Tyler, B. B. (1991). Strategic decision models: Integrating different perspectives. Strategic Management Journal, 12, 327-351.

Jackson, S. E., \& Dutton, J. E. (1988). Discerning threats and opportunities. Administrative Science Quarterly, 33, 370-387.

Lant, T. K., Milliken, F. J., \& Batra, B. (1992). The role of managerial learning and interpretation in strategic persistence and reorientation: An empirical exploration. Strategic Management Journal, 13, 585-608.

Mintzberg, H. (1994). The rise and fall of strategic planning. New York: Free Press. 
Mintzberg, H., Raisinghani, D., \& Theoret, A. (1976). The structure of "unstructured" decision processes. Administrative Science Quarterly, 21, 246-275.

Neuberg, S. L., \& Newsome, J. T. (1993). Personal need for structure: Individual differences in desire for simple structure. Journal of Personality and Social Psychology, 6, 113-131.

Olsen, M. D., Murthy, B., \& Teare, R. (1994). CEO perspectives on scanning the global hotel business environment. International Journal of Contemporary Hospitality Management, 6, 3-9.

Prahalad, C. K., \& Bettis, R. A. (1986). The dominant logic: A new link between diversity and performance. Strategic Management Journal, 7(6), 485-501.

Putnam, L. L., \& Wilson, C. E. (1982). Communicative strategies in organization conflicts: Reliability and validity of a measurement scale. In M. Burgoon (Ed.), Communication yearbook (Vol. 6, pp. 629-652). Newbury Park, CA: Sage.

Rajagopalan, N., Rasheed, A. M., \& Datta, D. K. (1993). Strategic decision processes: Critical review and future directions. Journal of Management, 19, 349-384.

Schneider, S. C., \& DeMeyer, A. (1991). Interpreting and responding to strategic issues: The impact of national culture. Strategic Management Journal, 12(4), 307-320.

Schwenk, C. R. (1995). Strategic decision making. Journal of Management, 21, 471-493. Starbuck, W. H. (1975). Organizations and their environments. In M. Dunnette (Ed.), Handbook of organizational psychology (pp. 1069-1123). Chicago: Rand McNally.

Starbuck, W. H., \& Milliken, F. J. (1988). Executives' perceptual filters: What they notice and how they make sense. In D. Hambrick (Ed.), The executive effect: Concepts and methods of studying top managers (pp. 35-66). Greenwich, CT: JAI.

Staw, B. M., Sandelands, L. E., \& Dutton, J. E. (1981). Threat-rigidity effects in organization behavior: A multilevel analysis. Administrative Science Quarterly, 26, 501-524.

Stubbart, C. I. (1989). Managerial cognition: A missing link in strategic management research. Journal of Management Studies, 26, 325-347.

Sutcliffe, K. M., \& Huber, G. P. (1998). Firm and industry as determinants of executive perceptions of the environment. Strategic Management Journal, 19, 793-807.

Ungson, G. R., Braunstein, D. N., \& Hall, P. D. (1981). Managerial information processing: A research review. Administrative Science Quarterly, 26, 116-134.

Walsh, J. (1988). Selectivity and selective perception: An investigation of managers' belief structures and information processing. Academy of Management Journal, 31, 873-896.

Walsh, J. (1995). Managerial and organizational cognition: Notes from a trip down memory lane. Organizational Science, 6, 280-321. 